\title{
Satisfaction With School Dental Service Provided by Mobile Dental Squads
}

Type: Article

Abstract:

Feedback on satisfaction with dental care is vital for continuous improvement of the service delivery process and outcome. The objective of this study was to assess the satisfaction with school dental service (SDS) provided via mobile dental squads in Selangor, Malaysia, under 4 domains of satisfaction: patient-personnel interaction, technical competency, administrative efficiency, and clinic setup using self-administered questionnaires. Among the 607 participants who had received treatment, $62 \%$ were satisfied with the services provided. In terms of domains, technical competency achieved the highest satisfaction score, whereas clinic setup was ranked the lowest. As for items within the domains, the most acceptable was "dental operator did not ask personal things which were not dentally related," whereas privacy of treatment was the least acceptable. In conclusion, whereas children were generally satisfied with the SDS, this study indicates that there are still areas for further improvement.

\begin{tabular}{|c|l|}
\hline Author & \multicolumn{1}{|c|}{$\begin{array}{l}\text { Othman, N. } \\
\text { Razak, I. A. }\end{array}$} \\
\hline Source & Asia-Pacific Journal of Public Health \\
\hline ISSN & $1010-5395$ \\
\hline DOI & $10.1177 / 1010539510370794$ \\
\hline Volume (Issue) & $22(4)$ \\
\hline Page & $415-425$ \\
\hline Year & 2010 \\
\hline
\end{tabular}

Keyword:

Satisfaction, dental treatment, school dental service, mobile dental, squad, care

Please Cite As:

OTHMAN, N. \& RAZAK, I. A. 2010. Satisfaction With School Dental Service

Provided by Mobile Dental Squads. Asia-Pacific Journal of Public Health, 22, 415-425. 
URL:

- $\quad$ http://apps.webofknowledge.com search via Accession No >> 000283101500005

- http://www.scopus.com/inward/record.url?eid=2-s2.078349233463\&partner|D=40\&md5=2d61434b6e4fc78e7f7083ca9ba5353d

- http://aph.sagepub.com/content/22/4/415

- $\quad$ http://www.ncbi.nlm.nih.gov/pubmed/20462854

- $\quad$ http://aph.sagepub.com/content/early/2010/05/10/1010539510370794.full.pdf 